\title{
The role of petal cell shape and pigmentation in pollination success in Antirrhinum majus
}

\author{
BEVERLEY J . GLOVER* \& CATHIE MARTIN \\ Department of Genetics, J ohn Innes Centre for Plant Science Research, Norwich Research Park, Norwich NR4 7UH, \\ U.K.
}

\begin{abstract}
The nature of the selective pressures which have resulted in the conical-papillate shape of the cells of the adaxial epidermis of many petals has been a matter for considerable speculation. One suggestion is that this shape focuses light within epidermal cells resulting in an increase in the amount of light absorbed by the floral pigments, intensifying the colour of the petals and possibly enhancing their attractiveness to potential pollinators; another is that conical cells aid pollinator orientation on the flower, either visually or when touched. The recent identification of a mutation at the MIXTA locus of Antirrhinum majus (which blocks the formation of conical petal cells) has allowed us to test this hypothesis. We report the results of field experiments indicating that, where pollinator number limits seed-set, flowers with conical epidermal cells receive more pollinator attention than do those with flat cells. Through the use of double mutants we have examined whether preferences for flowers with conical cells operate through the perception of flavonoid pigments. We have also examined the appearance of flowers with and without conical cells under ultraviolet light to determine whether differences in absorption or reflectance of light at these wavelengths may influence pollinator preference.
\end{abstract}

Keywords: Antirrhinum majus, competition, conical-papillate petal cells, flower colour, MIXTA, pollination.

\section{Introduction}

A factor which may reinforce the relationship between a plant and its pollinator is the depth of colour and the sheen on its petals, resulting from the shape of its epidermal cells. In one study (Kay et al., 1981) that examined the surface structures of 201 species of flower from 60 families, $79 \%$ were found to exhibit some form of conical or papillate cells on the adaxial epidermis (the epidermis orientated towards potential pollinators). It was proposed that conical or papillate cells increased the amount of light absorbed by the floral pigments, enhancing the perceived colour of the petal. Papillate cells would also scatter light reflected back from the mesophyll more evenly than would flat or lenticular (rounded) cells, resulting in a sparkling effect, or velvety texture to the petal (Kay et al., 1981; Kay, 1988). An alternative, although not mutually exclusive, explanation for the specialized shape of petal epidermal cells is that the texture of a flower may provide

*Correspondence. Present address: Department of Plant Sciences, University of Cambridge, Downing Street, Cambridge CB2 3EA, U.K. E-mail: bjg26@cam.ac.uk tactile signals that reinforce the pollination syndrome (the mechanisms by which plants and pollinators become attuned to each others' morphological traits), sensed through the sensilla trichodea on the tips of the antennae of insects (Kevan \& Lane, 1985). Although comparisons have been drawn between the relatively dull flowers of lenticular-celled species such as Solanum dulcamara and the brighter flowers of a papillate-celled species such as Primula veris, it was not possible to test the theory of the contribution of cell shape to pollinator attraction until the discovery of a species that produces flowers with both cell types.

Typical flowers of Antirrhinum majus (Scrophulariaceae) are a deep magenta in colour, with a velvety texture to the petal lobes (Fig. 1Ai). The petals form a flag structure, with a landing platform that requires a degree of mechanical pressure to force open the flower. The combination of these features suggests the syndrome of melittophily (Faegri \& Van der Pijl, 1966), and indeed the flowers are mostly pollinated by nectar-gathering bees. On the inner face of the lobes the epidermal cells are striated and papillate (Fig. 1Aii). These cells are mark- 

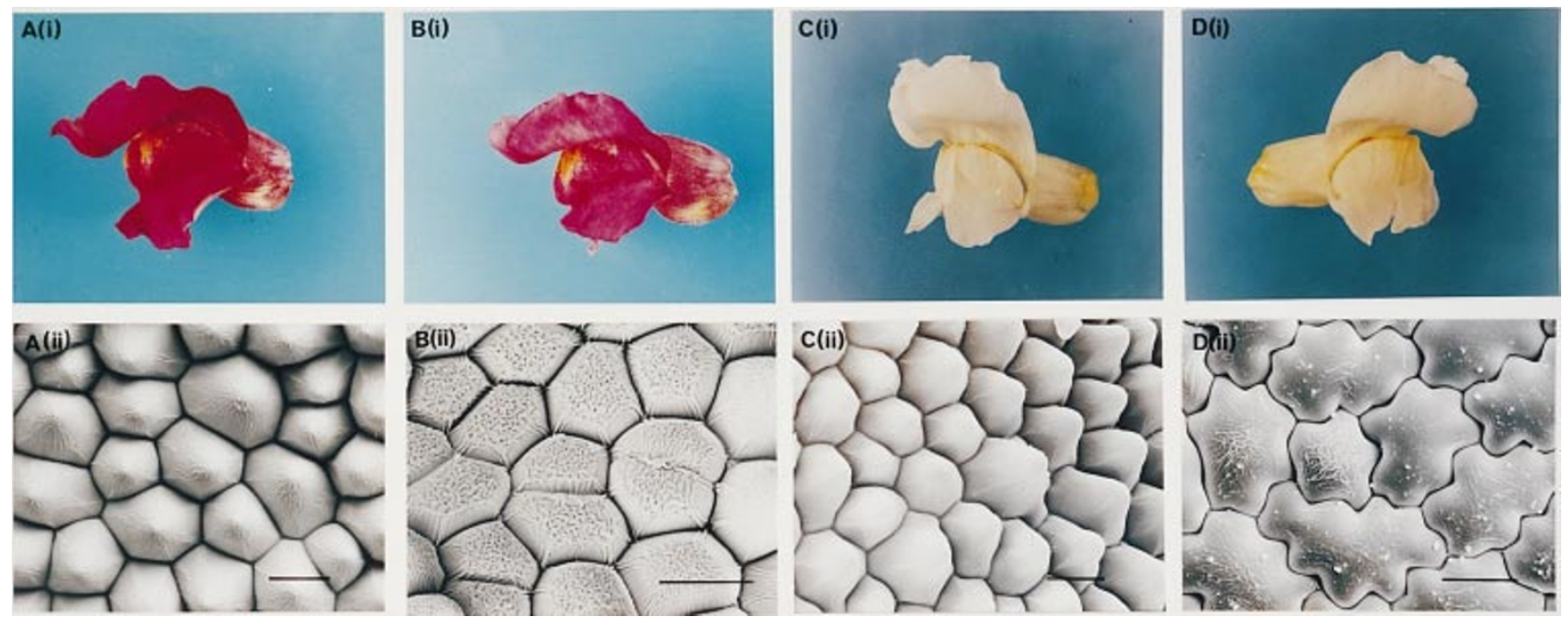

Fig. 1 Phenotypes of Antirrhinum majus lines described in text. A (i) Wild-type flower with magenta petals. A (ii) Scanning electron micrograph of wild-type petal, showing conical-papillate cells. Scale bar $=30 \mu \mathrm{m}$. B (i) mixta mutant flower with paler red petals. B (ii) SEM of mixta mutant petal, showing flattened epidermal cells. Scale bar $=30 \mu \mathrm{m}$. C (i) nivea mutant flower with acyanic petals. C (ii) SEM of nivea mutant petal, showing conical-papillate cells. Scale bar $=30 \mu \mathrm{m}$. D (i) nivea/mixta double-mutant flower with acyanic petals. D (ii) SEM of nivea/mixta double-mutant petal, showing flattened epidermal cells. Scale bar $=30 \mu \mathrm{m}$.

edly different from the epidermal cells on the outer face of the lobes, which are flat with an undulating margin, resembling leaf epidermal cells. The isolation of a line mutant at the mixta locus of $A$. majus (Noda et al., 1994) has allowed us to examine the role of these conical-papillate cells. Mutations at the mixta locus block the activity of a MYB-related transcription factor, and the subsequent activation of the mechanisms of directional cell expansion, so that the cells of the inner epidermis of the petal remain flat (Noda et al., 1994). Mutant flowers appear paler in colour, in spite of an equal amount of pigment, and have a dull texture, similar to that of the back of the petal lobes (Fig. 1Bi and 1Bii). In lines where the mutation is somatically unstable, flowers are produced with deeper red sectors on a pale mutant background. Noda et al. (1994) demonstrated by scanning electron microscopy that these sectors consist of islands of papillate cells on a background of flat cells. This system is therefore ideally suited to the testing of the theory that conical cells increase the attractiveness of a flower, and the well-characterized genetics of Antirrhinum have allowed us to compare the role of the topology of the surface of the petal to the role played by pigmentation.

The pigments which colour a flower have previously been shown to be a key component of a pollination syndrome. Faegri \& Van der Pijl (1966) suggested that brightly coloured flowers which contrast strongly with their background will be more readily discernible to pollinators. Floral colour is therefore thought to be an important characteristic of particular pollination syndromes. Evidence of pollinator preference for certain colours has been collected from a number of plant species. Whiteflowered forms of the larkspur, Delphinium nelsonii, produce fewer seed than the more common blueflowered form as a result of discrimination against white flowers by bumblebees and hummingbirds (Waser \& Price, 1981). Measurement of handling time of the two floral morphs showed that the whiteflowered plants require a longer handling time by the pollinators, as their inferior nectar guides reduce the ease of pollinator orientation (Waser \& Price, 1983). Studies on alfalfa, Medicago sativa, have shown that honey bees vary in their ability to discriminate between white- and purple-flowered plants (Clement, 1965), but that leaf-cutting bees prefer to visit purple flowers (Pedersen, 1967). Both bumble bees and honey bees have been shown to discriminate between purple- and white-flowered varieties of cowpea, Vigna sinensis; bumble bees visit purple flowers three times as often as they visit white flowers, but honey bees visit white flowers twice as often as purple flowers (Leleji, 1973). Butterflies have also been shown to exhibit flower colour preferences; Pieris rapae shows an extremely strong preference for the yellow-flowered morph of wild radish, Raphanus raphanistrum, over the whiteflowered morph (Kay, 1976). 
The floral pigments in Antirrhinum majus are flavonoids. The characteristic magenta colour of the wild-type flower results from cyanidin in the vacuoles of the petal epidermal cells. The biosynthetic pathway leading to the accumulation of cyanidin has been well described in Antirrhinum and the genes encoding many of the enzymes in the pathway have been isolated (Martin et al., 1991). The first committed step in the pathway is catalysed by chalcone synthase (CHS) which is encoded by a single gene, NIVEA (Wienand et al., 1982). Mutation at the NIVEA locus results in plants with white flowers which produce no light-absorbing flavonoids. The attractiveness of these flowers to pollinators relative to that of wild-type flowers should therefore provide a measure of the importance of pigmentation in the pollination syndrome of Antirrhinum.

The aims of this study were twofold; to test the hypothesis that conical-papillate cells in the petal epidermis are an adaptation which enhances pollination success; and to compare the contribution of conical cells with the contribution of pigmentation in the pollination syndrome of Antirrhinum.

\section{Materials and methods}

Plant material

A line of the mixta mutant which reverted to wildtype very rarely was used as a parent in a cross to the nivea mutant line. The progeny were selfed and seed of the $\mathrm{F}_{2}$ generation was grown and genotyped. The two parental lines were also selfed and genotyped, along with a wild-type line which had arisen as a germinal revertant from the mixta mutant line.

Plants were genotyped by DNA extraction and Southern blotting (Maniatis et al., 1982), and an individual homozygous for the mutant mixta allele $(\mathrm{mm})$ was selfed and the seed collected. The same procedure was used to generate seed homozygous for the wild-type Mixta allele $(M M)$, using a revertant line from which the transposon had excised. Seed was also obtained from a plant homozygous for the wild-type Mixta allele and homozygous for a mutation at the NIVEA locus (MMnn) (Spribille \& Forkmann, 1982; Wienand et al., 1982). The line used carries a deletion of the NIVEA locus so that no CHS is produced and consequently no flavonoids are made. These flowers are therefore white, lacking anthocyanins, aurones and also flavones and flavonols which absorb ultraviolet light (Fig. 1Ci and 1Cii). A double-mutant plant (mmnn) was also selected and seed was collected from this plant (Fig. 1Di, ii).
Tests of pollination frequency

In 1994 the seeds for the different genotypes were sown out and 48 young plants of each type (i.e. MMNN, mmNN, MMnn, mmnn; 192 in all) were grown on. When they reached several centimetres in height they were removed to random positions in an outdoor plot of four rows of 48 plants. This plot was, itself, part of a larger plot, of $\approx 50$ rows of 300 plants, containing Antirrhinum plants of numerous different genotypes affecting flower colour, flower shape, floral morphogenesis and leaf pigmentation.

In June, when the number of bees present in the field was at its height, four flower buds on the main spike of each plant were emasculated by removal of their anthers, and the buds were then reclosed. These flowers were tagged, and their seed pods collected one month later. In a second experiment in late July, when pollinator numbers had declined considerably, four flower buds from a lateral spike of each plant were emasculated and tagged, and after 3 days the flowers were bagged to prevent any further pollinator visits. These flowers were then left for a month to set seed, and the pods collected.

The following year, 48 plants of each type were again grown, but were organized according to two different random number series into two plots, each of four rows of 24 plants, again part of a larger plot. These plots were scored separately to allow for environmental differences and to provide replication of the experiment in different places together with replication over time. Four flower buds from the main spike of each plant were emasculated in early July, and another four in late July. This time the number of visitations was not limited by bagging the plants.

To confirm the genotyping of each plant the flowers were scored for pigment, and the pigmented flowers were scored for the mixta phenotype which caused them to appear paler and dull. It was not possible to score the mixta phenotype visually in the white flowers. The scoring of pigment phenotypes and the mixta phenotypes of the pigmented plants were compared to the expected genotypes and they corresponded exactly. Their accuracy allowed us to assume that the unpigmented flowers were also correctly ordered with respect to MIXTA alleles. A random sample of flowers from the nivea mutants was scored for their mixta phenotypes by cryoscanning electron microscopy, and this also confirmed that the random ordering matched that expected.

In the analysis of the data, the presence of a swollen seed pod was taken to indicate at least one pollinator visit, whereas an empty seed pod was

(C) The Genetical Society of Great Britain, Heredity, 80, 778-784. 
taken to represent an absence of any pollinating visitors. Flowers were therefore scored as having been visited or not.

\section{Analysis of pollination frequencies}

The pollination frequencies were compared by means of generalized linear modelling of each of the four data sets (June 1994, July 1994, early July 1995 and late July 1995). Comparisons were made between all components of the experimental design, in order to establish which, if any, interactions were statistically significant (Sokal \& Rohlf, 1981; McCullagh \& Nelder, 1983). Those comparisons which did not fit the idealized model generated by the GENSTAT general linear modelling program (assuming a Poisson distribution of data) were judged to be significant.

To ensure that different levels of female fertility were not influencing the results, 10 plants of each line were grown to maturity in the glasshouse. Ten flowers from each plant were selfed and scored for the percentage of flowers setting seed. These frequencies were compared by $\chi^{2}$ analysis.

Analysis of the visual effect of flat vs. conical and pigmented vs. unpigmented petal cells under ultraviolet light

To determine whether a difference in flower appearance was discernible under ultraviolet light (a wavelength range known to be visible to bees), wild-type, nivea, mixta and nivea/mixta mutant flowers were photographed under ultraviolet light. This was achieved by illuminating flowers with a hand-held ultraviolet lamp and excluding all visible light to the camera interior with an $18 \mathrm{~A}$ (Woods) filter. A 2 min exposure was required to achieve a clear image on monochromatic film. The absence of all other light to the camera interior was confirmed by retaking the photograph with a UV filter as well as an $18 \mathrm{~A}$ filter in place. The result was a completely blank piece of film. Test photographs taken in the field in natural daylight with the $18 \mathrm{~A}$ filter in place showed the same patterns of shade depth and intensity as seen on the photographs taken with artificial ultraviolet light, but were difficult to focus as the flowers moved in the wind during the exposure time, and, if picked, shrivelled slightly. Visual comparison of photographs taken outside with studio shots showed the latter to be a realistic representation of the natural situation.

\section{Results}

The numbers of flowers of each genotype which set seed in each of the plots at each of the sampling times are presented in Table 1 . These numbers are also expressed as percentages to allow comparisons in spite of the differences in the numbers of plants which survived to set seed and the very occasional reversion of the mixta mutant line to wild-type.

The most striking feature of these data is that the percentage of pollination events dropped as the summer progressed in both of the sampling years. This can be attributed to the reduced numbers of bees in the field, the short timespan allowed for pollination by the bagging of the flowers in 1994, and also by an increased tendency to nectar robbing as the season progressed.

It appeared that wild-type, magenta flowers were most frequently pollinated. There was variation in the pollination of mixta mutants between different times of the season and according to the presence or absence of pigment. However, for any particular plot at a particular time, flat-celled pigmented flowers

Table 1 Flowers of Antirrhinum majus pollinated as a proportion of flowers available for pollination

\begin{tabular}{lcccccc}
\hline Genotype & Early 94 & Late 94 & Early 95 1 & Early 95 2 & Late 95 1 & Late 95 2 \\
\hline MMNN & $198 / 212$ & $27 / 160$ & $47 / 68$ & $38 / 52$ & $59 / 93$ & $56 / 89$ \\
& $93.40 \%$ & $16.88 \%$ & $69.12 \%$ & $73.08 \%$ & $63.44 \%$ & $62.92 \%$ \\
$m m N N$ & $152 / 163$ & $1 / 85$ & $42 / 68$ & $58 / 82$ & $29 / 85$ & $36 / 89$ \\
& $93.25 \%$ & $1.18 \%$ & $61.76 \%$ & $70.73 \%$ & $34.12 \%$ & $40.45 \%$ \\
MMnn & $157 / 179$ & $6 / 57$ & $60 / 81$ & $57 / 80$ & $36 / 81$ & $25 / 80$ \\
& $87.71 \%$ & $10.53 \%$ & $74.07 \%$ & $71.25 \%$ & $44.44 \%$ & $31.25 \%$ \\
$m m n n$ & $141 / 181$ & $3 / 119$ & $51 / 80$ & $50 / 83$ & $21 / 76$ & $22 / 92$ \\
& $77.90 \%$ & $2.52 \%$ & $63.75 \%$ & $60.24 \%$ & $27.63 \%$ & $23.91 \%$ \\
\hline
\end{tabular}


were pollinated less than conical-celled pigmented flowers, and flat-celled white flowers were also pollinated less than conical-celled white flowers This suggested that the development of conical cells played an important role in attracting bees under all the conditions imposed during this experiment. To determine the relative significance of this role, a general linear model was fitted to the data to compare the effects of pigmentation and cell shape on the pollination success of flowers, and to determine whether there were any other significant interactions.

We identified no significant three-way or four-way interactions in any of the four data sets (early 1994, late 1994, early 1995, late 1995), indicating that the plot had no effect on pollination success in either of the two 1995 data sets, i.e. the environmental factors which differed between the two plots had no important effect. This also indicated that petal cell shape and pigmentation did not interact to affect pollination frequency, but were independent variables. The results of the tests on the two-way interactions between cell shape and pollination success are shown in Table 2, along with the same results for the interactions between pigmentation and pollination frequency.

The single most obvious conclusion to be drawn from these data is that the shape of the inner epidermal petal cells is a significant factor which affects the chances of a flower being visited by a pollinator. Those flowers with conical-papillate cells were more attractive to bees at all times, irrespective of whether they were pigmented or not. In the white flowers this could result from a visual effect invisible to the human eye, or from tactile stimulation of the bees, as suggested by Kevan \& Lane (1985).

Pigmentation did not play a significant role in pollination success in all data sets analysed (Table 2). In early 1994, and late 1995, the colour of the flowers did affect the frequency with which they were visited by pollinators. But in late 1994 and early 1995 colour was not a significant factor. This suggests that the pigmentation of Antirrhinum flowers, although sometimes important in attracting

Table 2 Values of $\chi^{2}$ for interactions of petal cell shape and pigmentation with fruit-set in Antirrhinum majus

\begin{tabular}{lcrcc}
\hline & Early 94 & Late 94 & Early 95 & Late 95 \\
\hline Cell shape & $5.5^{*}$ & $26.2^{* * *}$ & $4.0^{*}$ & $27.7^{* * *}$ \\
Pigment & $18.9^{* * *}$ & $0.6 \mathrm{NS}$ & $0.2 \mathrm{NS}$ & $25.4^{* * *}$ \\
\hline
\end{tabular}

$\chi^{2}$-statistics shown ( 1 d.f.). ${ }^{*} P<0.05,{ }^{* * *} P<0.005$. pollinators, is not as significant a factor as the effect of epidermal cell shape which, at least to the human eye, is a more subtle difference.

These data also demonstrate the importance of competition between plants for pollinator attention. When pollinators are abundant and pollination levels are very high, as in the early 1994 experiment, the importance of conical-papillate cells is diminished, along with the importance of pigmentation. However, when the numbers of pollinators are limiting, so that fewer flowers set seed, the difference between the pollination of wild-type, magenta flowers and pollination of unpigmented, or flatcelled flowers is greater.

The proportions of flowers manually self-pollinated in the glasshouse that set seed did not differ significantly among genotypes (MMNN, 0.96; $m m N N, 0.95 ;$ MMnn, 0.95; mmnn, 0.92).

Of the four varieties of flower that were photographed in a dark room, illuminated by ultraviolet light, and with a daylight filter in place, pigmented petals with conical epidermal cells (Fig. 2a) reflected less light than pigmented flat-celled petals (Fig. 2b). However, there was no discernible difference in ultraviolet photographs between the conical and flatcelled white flowers (Fig. 2c,d), mirroring the situation when the flowers are observed by daylight.

\section{Discussion}

The results of this competition experiment strongly suggest that the conical cells of the petal epidermis increase the attractiveness of a flower to its pollinators. Even a very slightly higher number of visitations of a certain phenotype by pollinators would ensure the rapid spread of the gene within a population, especially in an environment where pollinators are a limiting factor. Therefore the function of the MIXTA gene, which is necessary and sufficient for conical cell formation (B. Glover \& C. Martin, unpubl. data), has become an integral component of the Antirrhinum breeding system. These results also provide an explanation for the large numbers of plant species which produce petals with conicalpapillate epidermal cells (Kay et al., 1981).

Once an individual plant has developed such a feature which confers an advantage in pollination, the gene encoding it will establish rapidly. Recent work suggests that it is possible for a character to be fixed in a population by pollinator preference in a single generation (Galen, 1996).

To the human eye the presence or absence of conical petal cells affects the brightness of Antirrhinum flower pigmentation. However, in acyanic 
(nivea) flowers no effect of the conical cells can be observed. The fertility data suggest that pollinating insects can still detect a difference between conicaland flat-celled flowers that contain no anthocyanin. One possibility is that the cell shape affects reflectance of ultraviolet light so altering the appearance of the flowers to pollinators which see in this wavelength. Gorton \& Vogelmann (1996) confirmed that part of the effect of conical cells is to enhance visible pigmentation by comparing the ability of epidermal cells to focus light in the wild-type and mixta mutant lines of Antirrhinum. They found that conical cells focused light approximately twice as well as the mutant flat cells, and that this focusing was at a depth of $45-52 \mu \mathrm{m}$, well within the pigment-containing vacuole of the cells (which are around $60 \mu \mathrm{m}$ tall). However, the flat cells of the mixta mutant line produced maximal focal intensification at a depth of $60-75 \mu \mathrm{m}$, below the $25 \mu \mathrm{m}$-thick epidermis, in the unpigmented mesophyll tissue. The conical cells of the wild-type therefore appear deeper in colour as a result of the focusing of the captured light into the pigmented epidermal cells, rather than below them. Gorton \& Vogelmann (1996) also showed that the wild-type
Antirrhinum flowers reflected significantly less light than mixta mutant flowers, and absorbed significantly more. These differences can be attributed to the focusing of the light onto the light-absorbing anthocyanin pigments in the vacuoles of the epidermal cells, and to the reduction in reflection of light at low angles of incidence (Kay et al., 1981), which results in a greater depth of colour in wild-type flowers.

Comparison of the contribution of conical-papillate cells to securing pollinator attention with that of floral pigmentation resulted in the conclusion that pigmentation was of less significance than cell shape in attracting bees in Antirrhinum. The compound eyes of bees perceive different wavelengths of light than do vertebrate eyes, and may also perceive patterns of light waves being reflected from surfaces. The importance of conical papilllate petal cells to breeding systems is clear from their distribution throughout the angiosperms, in flowers of all colours including white.

The fact that the presence of conical-papillate cells enhanced the pollination frequency of the nivea mutant flowers suggests that these specialized cells do not result in increased pollinator attention solely
Fig. 2 Appearance of Antirrhinum majus flowers in ultraviolet light. (A) Wild-type flowers. (B) mixta mutant flowers, appearing paler than wildtype. (C) nivea mutant flowers, lacking pigmentation. (D) nivea/mixta double-mutant flowers.
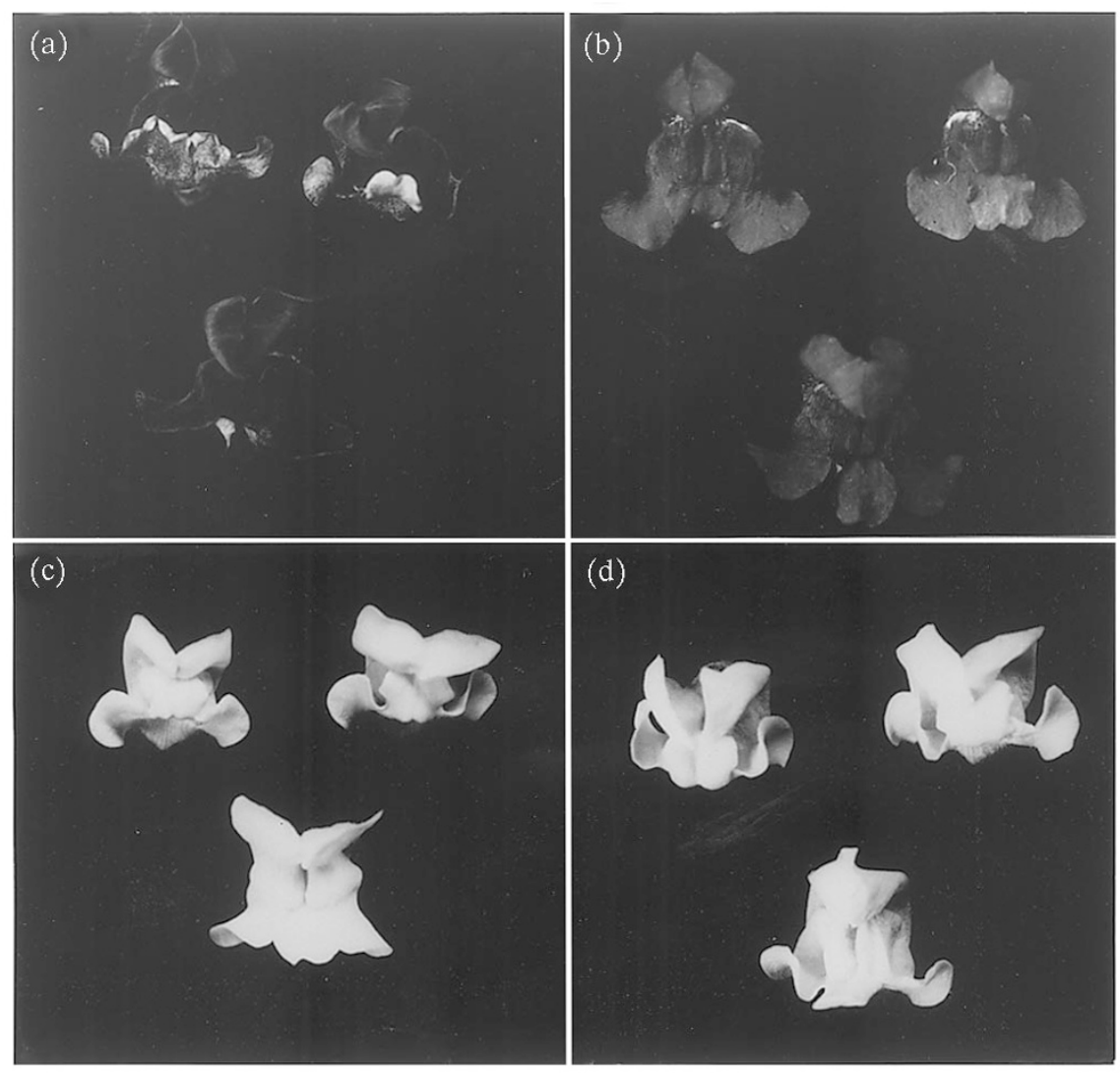
through a role in enhancing flower colour. It is possible that the flat-celled flowers reflect more light than the conical-celled ones, and thus appear brighter to the bee. Such a bright surface may not automatically suggest a petal to a pollinator, and may not therefore attract insects to visit the flower. An alternative explanation, suggested by Kevan \& Lane (1985), is that conical-papillate cells can be used as tactile clues to help the bee to orientate itself on the petal. We view this explanation as an unlikely one in Antirrhinum, as bees land on the conical-celled lobes of the flower straight away, and then move forward into the tube between these lobes. However, it is possible that the reflective properties of conical cells are used as a visual signal to aid orientation on the flower from a distance. A visual aid to orientation which would enable a bee to approach the flower directly and enter it immediately would cut down the handling time required for each flower, increasing the energy efficiency of the food source for the bee (Waddington, 1983).

In conclusion we have provided evidence that the conical-papillate cells of the inner epidermis of petals act to increase the pollinator attention received by the plant. Their effect on the behaviour of pollinators appears to be more substantial than the effect of pigmentation. These specialized cells may play additional roles in pollinator orientation, either tactilely or through the reflection of light.

\section{Acknow ledgements}

We would like to thank Steve MacKay for help with fieldwork, Barrie Allan for photography, Dr Judith Irwin for helpful comments on experimental design and statistical analysis, and Dr James Brown for advice on statistical analysis. B.J.G. acknowledges the support of a BBSRC PMB2 studentship during the course of this research.

\section{References}

CLEMENT, w. M., JR 1965. Flower color, a factor in attractiveness of alfalfa clones for honey bees. Crop Sci., 5, 267-268.

FAEGRI, K. AND VAN DER PIJL, L. 1966. The Principles of Pollination Ecology, 1st edn. Pergamon Press, Oxford.

GALEN, C. 1996. Rates of floral evolution: adaptation to bumblebee pollination in an alpine wildflower, Polemonium viscosum. Evolution, 50, 120-125.
GORTON, H. L. AND VOGELmanN, T. C. 1996. Effects of epidermal cell shape and pigmentation on optical properties of Antirrhinum petals at visible and ultraviolet wavelengths. $P l$. Physiol., 112, 879-888.

KAY, Q. O. N. 1976. Preferential pollination of yellowflowered morphs of Raphanus raphanistrum by Pieris and Eristalis spp. Nature, 261, 230-232.

KAY, Q. O. N. 1988. More than the eye can see: the unexpected complexity of petal structure. Plants Today, JulyAugust issue, 109-114.

KAY, Q. O. N., DAOUD, H. S. AND STIRTON, C. H. 1981. Pigment distribution, light reflection and cell structure in petals. Bot. J. Linn. Soc., 83, 57-84.

KEVAN, P. G. AND LANE, M. A. 1985. Flower petal microtexture is a tactile cue for bees. Proc. Natl. Acad. Sci. U.S.A., 82, 4750-4752.

LELEJI, O. I. 1973. Apparent preference by bees for different flower colours in cowpeas (Vigna sinensis (L.) Savi ex Hassk.). Euphytica, 22, 150-153.

MANIATIS, T., FRITSCH, E. F. AND SAMBROOK, J. 1982. Molecular Cloning. A Laboratory Manual. Cold Spring Harbor Laboratory Press, Cold Spring Harbor, NY.

MARTIN, C., PRESCOTT, A., MACKAy, S., BARTLETT, J. AND VRIJLANDT, E. 1991. Control of anthocyanin biosynthesis in flowers of Antirrhinum majus. Plant J., 1, 37-49.

McCUllagh, P. AND NELDER, J. A. 1983. Generalized Linear Models. Chapman \& Hall, London.

NODA, K.-I., GLOVER, B. J., LINSTEAD, P. AND MARTIN, C. 1994. Flower colour intensity depends on specialized cell shape controlled by a Myb-related transcription factor. Nature, 369, 661-664.

PEDERSEN, M. w. 1967. Cross-pollination studies involving three purple-flowered alfalfas, one white-flowered line, and two pollinator species. Crop Sci., 7, 59-62.

SOKAL, R. R. AND ROHLF, F. J. 1981. Biometry, 2nd edn. W. H. Freeman, New York.

SPRIBILLE, R. AND FORKMANN, G. 1982. Genetic control of chalcone synthase activity in flowers of Antirrhinum majus. Phytochemistry, 21, 2231-2234.

WADDINGTON, K. D. 1983. Foraging behavior of pollinators. In: Real, L. (ed.) Pollination Biology, pp. 213-239. Academic Press, Orlando, FL.

WASER, N. M. AND PRICE, M. V. 1981. Pollinator choice and stabilizing selection for flower color in Delphinium nelsonii. Evolution, 35, 376-390.

WASER, N. M. AND PRICE, M. V. 1983. Pollinator behaviour and natural selection for flower colour in Delphinium nelsonii. Nature, 302, 422-424.

WIENAND, U., SOMMER, H., SCHWARZ-SOMMER, Z., SHEPHERD, N., SAEDLER, H., KREUZALER, F. ETAL. 1982. A general method to identify plant structural genes among genomic DNA clones using transposable element induced mutations. Mol. Gen. Genet., 187, 195-201. 